\title{
Gene Expression Profiles in Murine Influenza Pneumonia
}

\author{
Mark C. Dessing ${ }^{a, b} \quad$ Koenraad F. van der Sluijs ${ }^{a, c, d} \quad$ C. Arnold Spek ${ }^{a, b}$ \\ Tom van der Poll ${ }^{a, b}$ \\ ${ }^{a}$ Center for Infection and Immunity Amsterdam, ${ }^{b}$ Center for Experimental and Molecular Medicine, \\ 'Laboratory of Experimental Immunology and ${ }^{\mathrm{d}}$ Department of Pulmonology, Academic Medical Center, \\ University of Amsterdam, Amsterdam, The Netherlands
}

\section{Key Words}

Multiplex ligation-dependent probe amplification •

Influenza pneumonia, murine $\cdot$ Gene expression

\begin{abstract}
Background: Many in vitro studies have focused on gene expression in influenza-infected leukocytes, lung tissue or cell lines. However, knowledge of in vivo gene expression in these compartments is limited. Methods: To obtain insight into gene expression profiles during influenza infection, we determined the expression of multiple genes by using a newly developed mouse-specific multiplex ligation-dependent probe amplification assay. Results: The genes involved in inflammation, Toll-like receptor signaling, coagulation, fibrinolysis, cell adhesion, tissue repair and homeostasis were measured in lung tissue, leukocytes in bronchoalveolar lavage fluid and tracheal epithelial cells in mice, before and after intranasal infection with influenza A. Most of the genes investigated were differentially expressed during the course of infection and returned to baseline levels when mice had recovered from the infection. However, expression of several genes remained altered even though mice had completely cleared the virus. Conclusion: These data provide the first information on compartmentalized gene expression profiles in the respiratory tract during influenza.
\end{abstract}

Copyright $\odot 2008$ S. Karger AG, Basel

\section{KARGER}

Fax +4161306 1234 E-Mail karger@karger.ch www.karger.com

\section{Introduction}

Respiratory influenza A infection is associated with symptoms such as fever, sore throat, sneezing and nausea. These symptoms usually start 2-4 days after infection and may last $1-2$ weeks $[1,2]$. Although most people infected with influenza recover, in rare cases infection may lead to life-threatening complications such as pneumonia. On average, 36,000 people per year die from influenza in the United States, and 114,000 per year are admitted to hospital as a result of this viral infection. Worldwide, between 250,000 and 500,000 people die from influenza infection each year, according to the World Health Organization (www.who.int/en/).

Influenza A virus primarily infects airway epithelial cells, but other cells like macrophages and leukocytes can also be infected [3]. Influenza-infected epithelial cells and leukocytes produce a variety of cytokines and chemokines $[4,5]$, and infection affects expression of Toll-like receptors (TLR) and TLR-adaptor molecules such as TRIF (Toll/IL-1 receptor-domain-containing adaptor inducing IFN- $\beta$ ) and MyD88 (myeloid differentiation primary response gene 88) [4, 6-10]. Besides inflammatory pathways, influenza virus can trigger the coagulation system. It increases the expression of tissue factor (TF), the main initiator of coagulation, in endothelial cells and monocytes in vitro $[11,12]$ and has recently been shown to in-

Dr. Mark C. Dessing

Department of Pathology, Academic Medical Center

Room L2-111, Meibergdreef 9

NL-1105 AZ Amsterdam (The Netherlands)

Tel. +31 20566 5645, Fax +31 20697 7192, E-Mail m.c.dessing@amc.uva.nl 
duce a prothrombotic state in mice by concurrent stimulation of coagulation and inhibition of fibrinolysis [13].

Several studies have examined the expression of a broad range of genes in mice and humans during infection with influenza [4, 14-20]. However, individual studies have focused on one specific compartment; for example, blood, lung tissue or epithelial cells. Knowledge of the dynamics and the extent of gene expression in several areas in the lung during influenza infection in vivo is relatively limited. Such knowledge may be important not only to obtain insight into the immune response to primary influenza infection but also for understanding the enhanced susceptibility to secondary bacterial pneumonia. Therefore, in the present study we sought to determine the relative expression of a set of 39 genes encoding cytokines, chemokines, proteins involved in coagulation and fibrinolysis, TLRs and associated proteins, and various other mediators implicated in the immune response to infection. We studied these factors at various time points after intranasal infection with influenza $\mathrm{A}$ in whole lung tissue, leukocytes harvested from bronchoalveolar lavage fluid (BALF) and respiratory epithelial cells obtained from mice.

\section{Materials and Methods}

\section{Animals}

Specific pathogen-free 8- to 10 -week-old male C57BL/6 mice (WT) were purchased from Charles River (Maastricht, The Netherlands). All experiments were approved by the Animal Care and Use Committee of the University of Amsterdam.

\section{Virus Infection}

The model of influenza pneumonia has been previously described in detail $[21,22]$. Briefly, mice were anesthetized by inhalation of isoflurane (Abbott Laboratories, Maidenhead, UK) and inoculated intranasally with $50 \mu \mathrm{l}$ of PBS containing 1,400 viral copies of influenza A/PR/8/34 (ATCC VR-95, Rockville, Md., USA). Mice were sacrificed before infection and 2, 8 and 14 days after infection for the measurements described below.

\section{Preparation of Whole Lung Homogenates}

Mice were anesthetized with Hypnorm (Janssen Pharmaceutica, Beerse, Belgium) and midazolam (Roche, Meidrecht, the Netherlands). Lungs were harvested and homogenized at $4^{\circ} \mathrm{C}$ in 5 volumes of sterile isotonic saline with a tissue homogenizer (Biospec Products, Bartlesville, Okla., USA). $100 \mu$ l of lung homogenate was immediately dissolved in Trizol (Invitrogen, Breda, the Netherlands) and RNA was prepared according to the manufacturer's protocol. Determination of the viral load was done using real-time quantitative PCR [23].

\section{Bronchoalveolar Lavage}

Bronchoalveolar lavage was performed in separate mice, as described previously $[21,22]$. Briefly, the trachea was exposed through a midline incision, cannulated with a sterile 22-gauge Abbocath-T catheter (Abbott, Sligo, Ireland) and two 0.5-ml aliquots of sterile PBS were instilled and retrieved thereafter. For cell count and differentiation: BALF was spun at $1,500 \mathrm{rpm}$ for 10 min, cells were resuspended in $100 \mu$ l of PBS and counted by a Z2 Coulter particle count and size analyzer (Beckman-Coulter Inc., Miami, Fla., USA). Differential cell counts were determined on cytospin preparations stained with Giemsa stain (Diff-Quick, Baxter, UK). For RNA preparations, BALF was spun at 1,500 rpm for $5 \mathrm{~min}$, the cell pellet was immediately dissolved in Trizol and RNA was prepared according to manufacturer's protocol.

\section{Brush-Obtained Lung Epithelial Cells}

To obtain RNA from lung epithelial cells, the trachea was excised at the bifurcation of the bronchi and opened via longitudinal incision. Epithelial cells were scraped from the interior of the trachea using a sterile cotton stick, which was placed in Trizol immediately thereafter. Several minutes later, the cotton stick was removed and the RNA was prepared according to the manufacturer's protocol.

\section{Multiplex Ligation-Dependent Probe Amplification}

RNA was analyzed by multiplex ligation-dependent probe amplification (MLPA), as has been previously described for human samples [24-26]. Briefly, total RNA was used to prepare cDNA using gene-specific RT primers. After the formation of cDNA, both the MLPA probes hybridize to immediately adjacent target sequences. Following ligation of the probes, the so-derived singlestrand probe fragment is amplified by PCR using 2 different primers. Each probe generates an amplification product of unique length that is detected by electrophoresis. The size of this PCR fragment, which is dependent on the length of the stuffer region, identifies the amplified gene (details about MLPA can be found at www.mrc-holland.com). In collaboration with MRC-Holland (Amsterdam, the Netherlands) we developed a mouse-specific kit for the simultaneous detection of $39 \mathrm{mRNA}$ molecules (online suppl. tables 1 and 2, www.karger.com/doi/10.159/000167961). This set was designed to obtain a global insight into the induction of several inflammatory pathways implicated in the host response to infection. All samples were tested with the same batch of reagents. The levels of mRNA for each gene were expressed as a normalized ratio of the peak area divided by the peak area of the housekeeping gene, transferrin receptor (TFRC; P90, CD71) [27], resulting in the relative abundance of mRNAs of genes of interest [24-26]. Results for relative gene expression were similar when expressed against another housekeeping gene, TATA-box binding protein (TBP; data not shown).

Assays

Whole lung homogenates were processed as described previously [28]. Tumor necrosis factor (TNF)- $\alpha$, interleukin (IL)-6, IL10 and interferon (IFN) $-\gamma$ were measured by ELISA (R\&D Systems, Abingdon, UK).

\section{$R T-P C R$}

cDNA synthesis was performed as described previously [29]. cDNA was amplified using real-time quantitative PCR (Lightcycler Sequence Detector System, Roche, Mannheim, Germany). The following primers were used: 5'-CAGGAGCCAAGAGTGAAGAAC-3' (forward) and 5'-GGAAATAATTCTGGCT- 
CATAGCTACT-3' (reverse) for TBP, 5'-GAACAACGATGATGCACTTG-3' (forward) and 5'-TGAAGGACTCTGGCTTTGTC-3' (reverse) for IL-6, 5' -TCCTTGGGAAGCAATTGAAG-3' (forward) and 5'-AGTAGGGAACCCTCTGAGC-3' (reverse) for IL-10, 5'-AAGAGGAAGCCCAAGAAAGC-3' (forward) and 5'CGATGGAATCGATGATGTTG-3' (reverse) for TLR2 and $5^{\prime}$ ACCTGGCTGGTTTACACGT-3' (forward) and 5'-CTGCCAGAGACATTGCAGAA-3' (reverse) for TLR4. TLR2, TLR4, IL-6 and IL-10 mRNA expression levels were normalized for the amount of TBP mRNA present in each sample.

\section{Statistical Analysis}

Values are expressed as mean \pm SEM. Differences between 2 groups were analyzed by Mann-Whitney test. Differences between more than 2 groups were analyzed by 1-way analysis of variance. $\mathrm{p}<0.05$ was considered statistically significant.

\section{Results}

\section{Induction of Influenza Pneumonia}

In accordance with previous reports from our laboratory $[21,22,28,29]$, intranasal infection with 1,400 viral copies of influenza $\mathrm{A} / \mathrm{PR} / 8 / 34$ resulted in a transient weight loss reaching a nadir 8 days after infection (fig. 1a; $\mathrm{p}<0.05$ compared to day 0 ). Body weight had recovered to baseline at day 14 . The viral load was determined 2, 8 and 14 days after infection (fig. 1b). Two and 8 days after infection, the viral load had increased considerably, but at day 14 the influenza virus was cleared from the lungs. It should be noted that we measured viral load by realtime quantitative PCR instead of a standard plaque assay. These methods may differ in their outcome, since a standard plaque assay only detects viable virus (i.e. virus that has been shed by infected cells), whereas molecular techniques detect all viral particles. The cellular composition of BALF did not change during the first 2 days of the infection and mainly consisted of macrophages and very few neutrophils (fig. 1c). At day 8, total leukocyte count in BALF had increased approximately 8 -fold compared to day 0 , which was caused by an influx of macrophages, neutrophils, monocytes and lymphocytes. The number of macrophages tended to be higher at day $8(\mathrm{p}=0.06)$ and remained significantly increased at day 14 compared to day 0 ( $\mathrm{p}<0.05)$. Total neutrophil count was significantly increased at day $8(\mathrm{p}<0.01)$ and modestly increased at day $14(\mathrm{p}=0.06)$ compared to day 0 . At day 14 , no lymphocytes or monocytes could be detected in BALF. Cytologic analysis of brushed epithelial cells (hereafter referred to as BRUSH) showed no infiltrating leukocytes at any time point (data not shown).
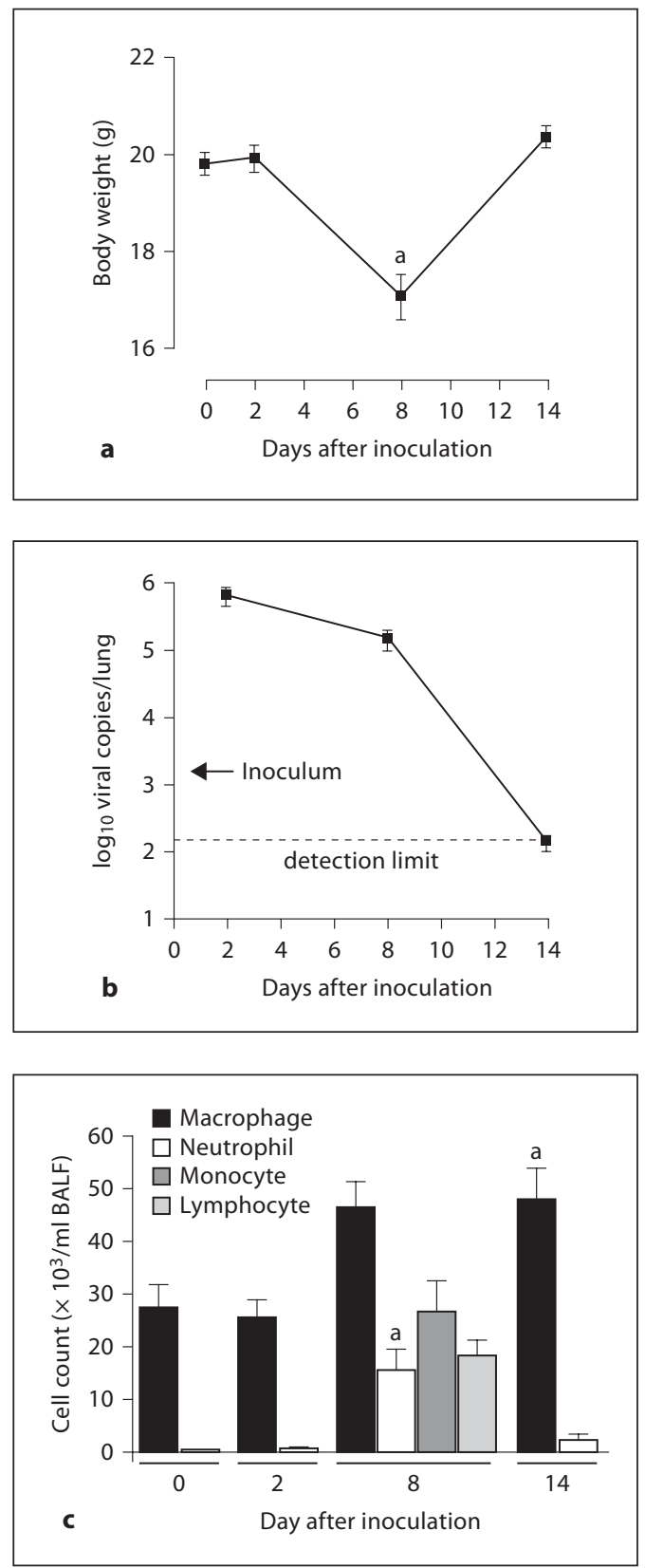

Fig. 1. Body weight (a), pulmonary viral load in lung homogenates (b) and cell composition of BALF (c) during influenza infection in WT mice. Data are mean \pm SEM ( $\mathrm{n}=8$ per group). ${ }^{\mathrm{a}} \mathrm{p}<0.05$ vs. uninfected mice (day 0 ).

Cytokine and Chemokine mRNA Gene Expression

To determine mRNA expression of several cytokines and chemokines, we analyzed mRNA profiles in lung tissue, leukocytes present in BALF and BRUSH. mRNA expression of IL-6, IL-1 $\beta$, IL-10, TNF- $\alpha$, IFN- $\gamma$ and macrophage inflammatory protein-1 $\alpha$ (MIP-1 $\alpha$ ) was detectable 


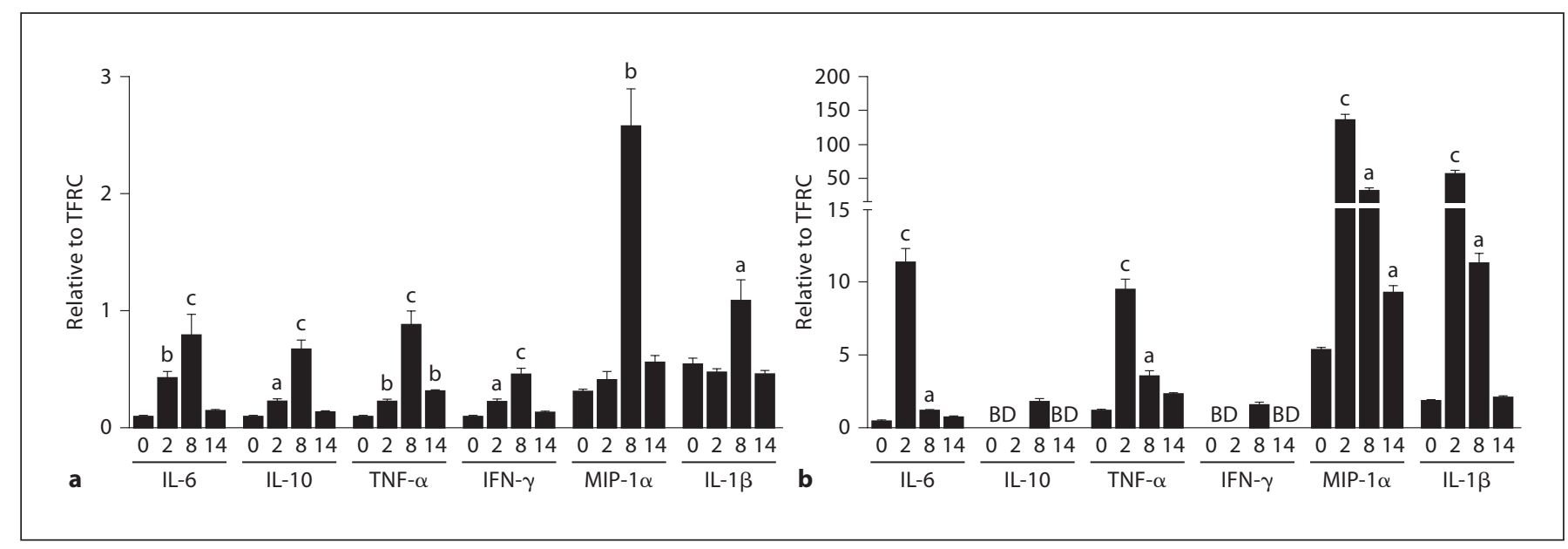

Fig. 2. mRNA expression of several cytokines and chemokines. Naïve or influenza-infected mice were sacrificed at specific timepoints and mRNA was extracted from either lung tissue (a) or BALF cells (b). mRNA was measured by MLPA as described in the
Methods section. Data are mean \pm SEM (lung: $n=8$ per group, BALF: $\mathrm{n}=5$ per group). ${ }^{\mathrm{a}} \mathrm{p}<0.05,{ }^{\mathrm{b}} \mathrm{p}<0.01,{ }^{\mathrm{c}} \mathrm{p}<0.001$ vs. uninfected mice. $\mathrm{BD}=$ Below detection limit.
Table 1. mRNA expression in whole lung homogenate by RT-PCR ( $\mathrm{n}=8$ per group)

\begin{tabular}{lcl}
\hline & Day 0 & Day 8 \\
\hline IL-6 & $109 \pm 27$ & $267 \pm 39^{\mathrm{a}}$ \\
IL-10 & $31 \pm 12$ & $903 \pm 221^{\mathrm{b}}$ \\
TLR2 & $59 \pm 9$ & $182 \pm 14^{\mathrm{b}}$ \\
TLR4 & $281 \pm 66$ & $571 \pm 122$ \\
\hline
\end{tabular}

Data are arbitrary units and are means \pm SEM. mRNA expression levels were normalized for the amount of TBP mRNA present in each sample. ${ }^{\mathrm{a}} \mathrm{p}<0.005,{ }^{\mathrm{b}} \mathrm{p}<0.0005$ vs. day 0.

in lung tissue and BALF cells (fig. 2). Of these, only MIP$1 \alpha$ mRNA was detectable in BRUSH but did not alter during the course of infection (data not shown). mRNA expression of IL- 6 , IL-1 $\beta$, IL-10, TNF- $\alpha$, IFN- $\gamma$ and MIP- $1 \alpha$ increased significantly during the course of infection and, except for TNF- $\alpha$ expression in lung tissue, returned to baseline level at day 14 (when the mice had recovered from the infection). mRNA expression of cytokines and chemokines in general peaked earlier in BALF cells (2 days after infection) than in whole lung homogenates ( 8 days after infection), with the exception of IL-10 and IFN- $\gamma$ mRNAs. To confirm data obtained by MLPA, RT-PCR analyses for IL- 6 and IL-10 were performed on mRNA from whole lung homogenates from mice before infection
Table 2. Protein expression in whole lung homogenates $(n=4-8$ per group)

\begin{tabular}{lrllr}
\hline & Day 0 & Day 2 & Day 8 & \multicolumn{1}{c}{ Day 14 } \\
\hline IL-6, pg/ml & $3.3 \pm 0.2$ & $136.1 \pm 24.3^{\text {c }}$ & $178.5 \pm 32.9^{c}$ & $9.9 \pm 2.3$ \\
IL-10, pg/ml & $21.4 \pm 8.8$ & $61.5 \pm 8.1^{\text {a }}$ & $164.5 \pm 20.3^{c}$ & $48.5 \pm 7.4$ \\
TNF- $\alpha, p g / m l$ & $8.5 \pm 0.3$ & $29.0 \pm 9.0^{c}$ & $122.9 \pm 17.3^{c}$ & $11.7 \pm 5.3$ \\
IFN- $\gamma, \mathrm{pg} / \mathrm{ml}$ & $2.5 \pm 0.2$ & $3.3 \pm 0.2$ & $23.4 \pm 1.7^{\mathrm{b}}$ & $3.8 \pm 0.2$
\end{tabular}

Data are means \pm SEM.

${ }^{\mathrm{a}} \mathrm{p}<0.05,{ }^{\mathrm{b}} \mathrm{p}<0.01,{ }^{\mathrm{c}} \mathrm{p}<0.005$ vs. day 0.

(day 0 ) and 8 days after infection (table 1). In addition, protein expression of IL-6, IL-10, TNF- $\alpha$ and IFN- $\gamma$ was determined in whole lung homogenates before infection (day 0), and 2, 8 and 14 days after infection (table 2), which confirmed the mRNA expression profiles.

\section{Toll-Like Receptor and Associated Proteins}

Figure 3 shows mRNA expression of TLRs, CD14, MD-2 and proteins involved in TLR signaling in lung tissue, BALF cells and BRUSH. mRNA expression of TLR2, TLR4, CD14, MD-2, IRAK-1 (interleukin-1 receptor-associated kinase), IRAK-3 and NFKBIA (nuclear factor of kappa light chain gene enhancer in B-cell inhibitor- $\alpha$ ) were detectable in all 3 compartments, whereas TLR9 


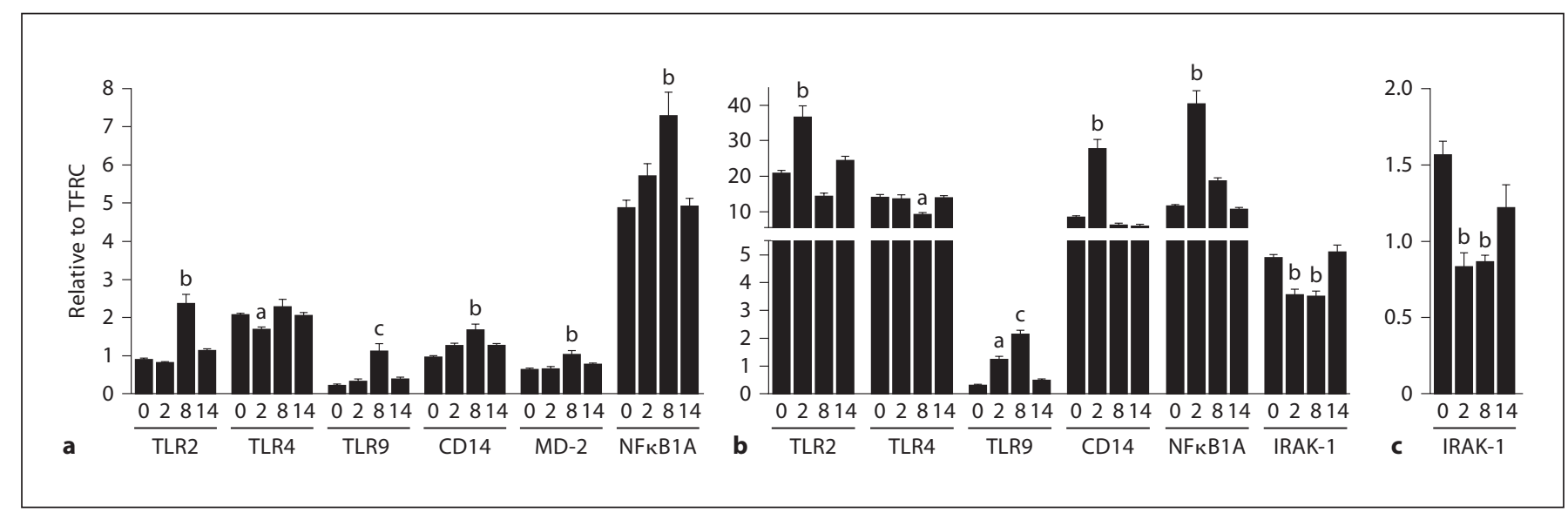

Fig. 3. mRNA expression of TLRs and related molecules. Naïve or influenza-infected mice were sacrificed at specific timepoints and mRNA was extracted from lung tissue (a), BALF cells (b) or BRUSH (c). mRNA was measured by MLPA as described in the
Methods section. Data are mean \pm SEM (lung and BRUSH $n=8$ per group, BALF $\mathrm{n}=5$ per group). ${ }^{\mathrm{a}} \mathrm{p}<0.05,{ }^{\mathrm{b}} \mathrm{p}<0.01,{ }^{\mathrm{c}} \mathrm{p}<0.001$ vs. uninfected mice.
mRNA was only detectable in lung tissue and BALF cells. mRNA expression profiles during the course of the infection were largely similar in whole lung homogenates and BALF cells, with particular increases in mRNA levels for TLR2, TLR9, CD14, MD-2 and NF-кBIA, and decreases in mRNA levels for TLR4. IRAK-1 mRNA remained stable in lung homogenates but decreased in BALF cells and BRUSH. All mRNAs had returned to baseline levels 14 days after infection. To confirm data obtained by MLPA, RT-PCR analyses for TLR2 and TLR4 were performed on mRNA from whole lung homogenates from mice before (day 0 ) and 8 days after infection (table 1).

\section{Coagulation and Fibrinolysis}

Figure 4 shows mRNA expression of several mediators involved in coagulation and fibrinolysis in lung tissue, BALF cells and BRUSH. mRNA levels of TF, tissue factor pathway inhibitor (TFPI) and urokinase-receptor plasminogen activator (uPAR) were detectable in all $3 \mathrm{com}$ partments. mRNA levels of plasminogen activator inhibitor 1 (PAI-1) were detectable in lung tissue and BALF cells, mRNA levels of coagulation factor II receptor (PAR1) and coagulation factor II receptor-like 1 (PAR-2) were detectable in lung tissue and BRUSH, and tissue plasminogen activator (tPA) mRNA was only detectable in lung tissue. Changes in mRNA levels were especially clear at day 8. At this time point, TF and uPAR mRNA levels were increased in lung tissue but decreased in BALF cells and BRUSH. Similarly, PAI-1 mRNA was elevated in lung tissue and decreased in BALF cells. TFPI mRNA levels de- clined in both lung tissue and BALF cells, whereas tPA mRNA levels increased in lung tissue. PAR mRNAs displayed few alterations during influenza, with the exception of PAR-1 mRNA which was lower 8 days after infection. mRNA expression of most coagulation and fibrinolysis mediators had returned to baseline levels at day 14 , although the expressions of uPAR in BRUSH and tPA in lung tissue remained altered.

\section{Cell Adhesion, Tissue Repair and Homeostasis \\ Molecules}

Figure 5 shows mRNA levels of integrins, metallopeptidases and related molecules in lung tissue, BALF cells and BRUSH. Detectable levels of ICAM-1 (intercellular adhesion molecule), ITGA-V (integrin- $\alpha-\mathrm{V}$ ) and HIF- $1 \alpha$ (hypoxia inducible factor- $1 \alpha$ ) mRNAs were measured in all 3 compartments. Haptoglobin (HP) mRNA expression was detectable in lung tissue and BRUSH, ITGA-5 mRNA expression was detectable in lung tissue and BALF cells, whereas endothelial cell nitric oxid synthase, MMP2 (matrix metallopeptidase-2) and ITGB-3 (integrin- $\beta-3$ ) mRNAs were only detectable in lung tissue. The mRNAs of these mediators were differentially expressed during the course of infection in the 3 compartments studied. The most consistent changes were found in BALF cells. In these, increases in the mRNAs for ICAM-1, ITGA-V and HIF- $1 \alpha$ were detected. Fourteen days after infection, most mRNAs had returned to baseline levels except for ITGA-V mRNA in BALF cells and HP, MMP-2 and ITGB3 mRNAs in lung tissue. 


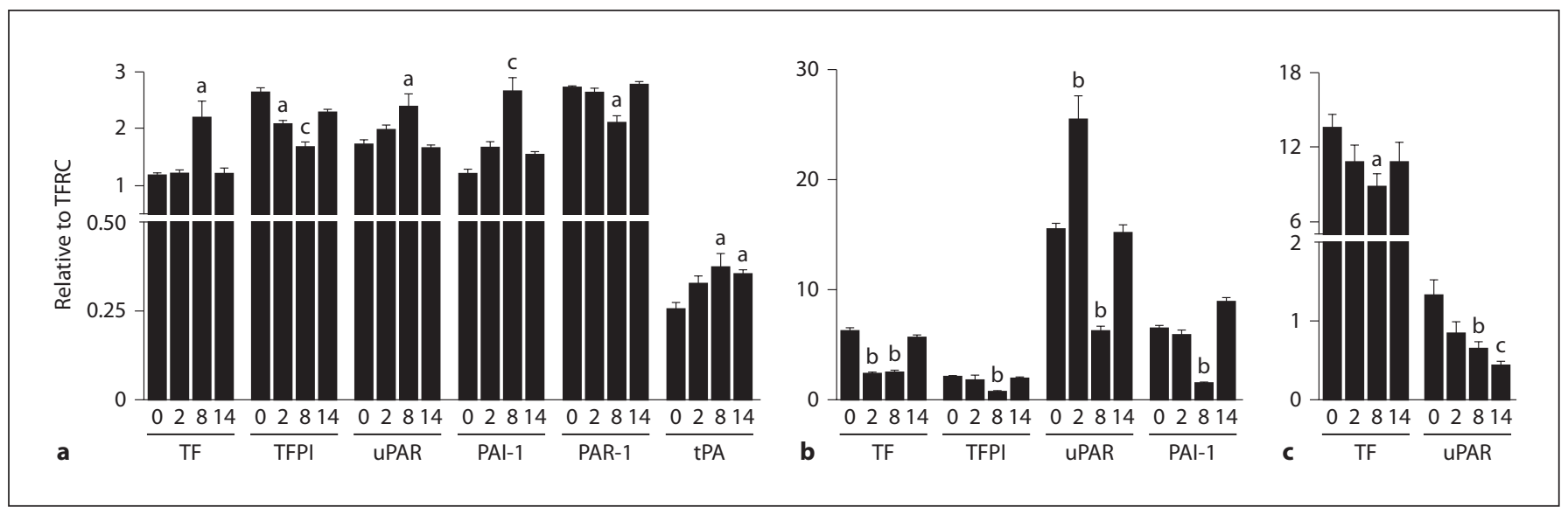

Fig. 4. mRNA expression of mediators involved in coagulation and fibrinolysis. Naïve or influenza-infected mice were sacrificed at specific timepoints and mRNA was extracted from lung tissue (a), BALF cells (b) or BRUSH (c). mRNA was measured by MLPA as described in the Methods section. Data are mean \pm SEM (lung and BRUSH: $\mathrm{n}=8$ per group, BALF: $\mathrm{n}=5$ per group). ${ }^{\mathrm{a}} \mathrm{p}<0.05$, ${ }^{\mathrm{b}} \mathrm{p}<0.01,{ }^{\mathrm{c}} \mathrm{p}<0.001$ vs. uninfected mice.

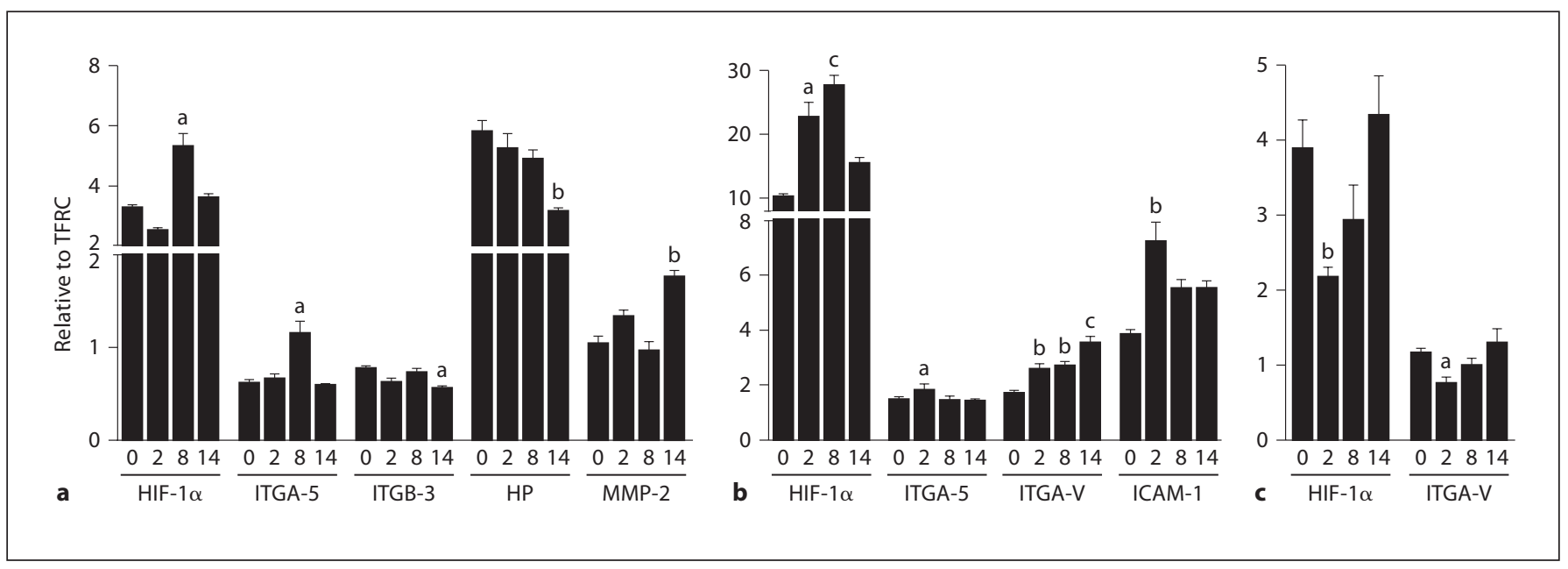

Fig. 5. mRNA expression of integrins, tissue repair molecules and others. Naïve or influenza-infected mice were sacrificed at specific timepoints and mRNA was extracted from lung tissue (a), BALF cells (b) or BRUSH (c). mRNA was measured by MLPA as described in the Methods section. Data are mean \pm SEM (lung and BRUSH $\mathrm{n}=8$ per group, BALF $\mathrm{n}=5$ per group). ${ }^{\mathrm{a}} \mathrm{p}<0.05$, ${ }^{\mathrm{b}} \mathrm{p}<0.01,{ }^{\mathrm{c}} \mathrm{p}<0.001$ vs. uninfected mice.

\section{Discussion}

Influenza is a common cause of upper respiratory tract infection and pneumonia. Although several studies have examined the host inflammatory response to influenza infection, our investigation represents the first attempt to evaluate the time-dependent expression of a set of inflammatory genes in 3 compartments within the lung (whole lung homogenates, BALF cells and tracheal epithelial cells) after inoculation with influenza A virus via the airways. For this, we developed a mouse-specific MLPA kit that enables the simultaneous quantitative measurement of a range of genes involved in inflammation, TLR signaling and the coagulation and fibrinolysis pathways. Many of these genes were differentially expressed during the course of infection, returning to basal 
expression levels upon recovery 14 days after viral inoculation.

MLPA is a recently described technique that can detect 1-copy number changes of chromosomal DNA sequences [24]. The benefit of MLPA over whole genome microarrays is that the MLPA is a more targeted technique to analyze genes of interest. By using MLPA, one can (semi)quantitatively assess the extent of up- or downregulation of genes. The disadvantage of MLPA is that, in contrast to whole genome microarrays, it does not detect altered expressions of genes not included in the assay. Studies in humans have indicated the usefulness of this technique for relative quantification of up to 40 different mRNAs in a single reaction using very small amounts of sample RNA (equivalent to $10 \mu$ l of whole blood) [25]. As such, MLPA represents a valuable tool to study gene expression profiles in small animals. To test the newly developed mouse-specific MLPA assays, we chose the influenza model as it is a widely studied infection. RT-PCR analysis of several genes and cytokine levels measured by ELISA confirmed the data obtained by MLPA. To our knowledge this article is the first to describe the use of MLPA in mice. We show that the gene expression profiles obtained by the mouse-specific MLPA resemble results from earlier studies (see below).

Many in vitro studies of influenza-induced cytokine production have been carried out in murine, rat or human monocytes/macrophages. The production of IFN- $\alpha$, TNF- $\alpha$, IL- 6 , and the chemokines MIP- $1 \alpha$, MIP- $1 \beta$, MCP-1, MCP-3, IP-10 and RANTES in cell culture has been documented [5]. Importantly, epithelial cells are the primary target cells of influenza and expression and production of IL-6, IL-8 and RANTES by influenza-infected epithelial cells have been reported [5]. In mouse studies, infection with influenza enhanced mRNA expression in lung tissue of MIP- $1 \alpha$, MIP-1 $\beta$, MIP-2, IP-10, RANTES and MCP-1 $[30,31]$. In addition, production of IL-1 $\beta$, IL6 , TNF- $\alpha$ and IFN- $\gamma$ have been shown to increase, both in BALF and whole lung homogenates, during infection with influenza [21, 28, 32, 33].

In our study, mRNA expression of several cytokines and the chemokine MIP-1 $\alpha$ were upregulated in lung tissue and BALF cells during the course of the infection, returning to baseline levels at day 14 (when mice had recovered from the infection). mRNA expression of IL-6, IL- $1 \beta$, TNF- $\alpha$ and MIP- $1 \alpha$ in BALF cells was significantly upregulated 2 days after infection and they were most likely to be expressed in resident alveolar macrophages, which are the main type of leukocyte present (approximately 95\%) at that time and which is indicative of the activated state on day 2 after infection. We do not know, however, if macrophages are directly triggered by viral infection or by factors secreted by epithelial cells. It is important to note that these mediators are already downregulated in BALF cells on day 8 after viral infection, which suggests that other (migrating) inflammatory cells are less efficient in the production of these mediators. IL10 and IFN- $\gamma$ mRNA expression was detectable 8 days after infection. IL-10 and, especially, IFN- $\gamma$ are mainly produced by $\mathrm{T}$ lymphocytes. The expression profiles of these mediators corresponded with the cell influx seen in BALF after influenza infection. We chose not to perform MLPA on purified cell populations from BALF or lung tissue in order to avoid artificial alterations in gene expression profiles due to the purification procedures. Together, these data demonstrate the immunokinetics of several cytokines and chemokines in mice during infection with influenza.

TLRs are pattern-recognition receptors which recognize specific molecules expressed by bacteria and viruses [34]. TLRs are expressed by a wide range of leukocytes, including cells from the innate immune system such as macrophages/monocytes, neutrophils and dendritic cells, and also epithelial cells. In general, binding of a pathogen-related molecule to a TLR induces the recruitment of intracellular adaptor proteins to the TLR and the activation of several kinases, which ultimately leads to the translocation of nuclear transcription factors and the transcription of several genes encoding pro- and anti-inflammatory cytokines, chemokines and interferons [34].

Several studies have shown that during infection of human epithelial cells, macrophages and neutrophils altered TLR expression $[4,9,10]$. A study performed by Seki et al. [35] showed that mice infected with influenza had increased mRNA expression of TLR2, TLR4, TLR5 and TLR9 in lung tissue compared to uninfected mice. In this study, we showed that during infection with influenza, mRNA expression of TLR2 and TLR9, and also CD14, MD-2 and NFкBIA was upregulated in lung tissue and that, except for MD-2, this was also observed in leukocytes from BALF. Two days after infection, macrophages are the most abundant leukocytes in BALF, and the alterations in mRNA expression of TLR2, TLR9, CD14, NFкBIA and IRAK-1 most likely originated from these resident alveolar macrophages.

The reduced mRNA expression of TLR4 in leukocytes in BALF 8 days after infection could be explained by a the relatively reduced expression of TLR4 in all leukocytes or by an influx of leukocytes with a lower TLR4 expression. We would have expected an increase in TLR4 mRNA ex- 
pression during infection with influenza [35]. However, altered TLR4 mRNA expression was not observed in lung tissue in our model. Little difference in TLR mRNA expression was observed in brush-obtained tracheal epithelial cells except for downregulation of IRAK-1 mRNA during the course of infection, which returned to the baseline level 14 days after infection. Infection or stimulation of epithelial cells with influenza, IFN or poly(I:C), a synthetic compound known to mimic double-stranded RNA of viral origin, is known to alter mRNA expression of TLRs and related molecules $[4,6,9,36]$. Notably, cells obtained from the trachea by the brush procedure do not include pulmonary bronchial or alveolar epithelial cells, which are frequently used in experiments in vitro. Therefore we do not exclude the possibility of altered TLR mRNA expression in mouse bronchial or alveolar epithelial cells during infection with influenza. These data show that during infection with influenza, mRNA expression in numerous TLRs and related molecules is differentially affected. The reduced expression of IRAK-1 and the enhanced expression of the NFкB inhibitor NFкBIA 2 days after infection suggest a suppression of the TLR pathway in BALF cells early after the appearance of influenza A virus in the respiratory tract.

The coagulation system is a tightly controlled system with several proteins and receptors that control fibrin formation and degradation. Proteins involved in the coagulation system are TF, TFPI, PAR-1 and PAR-2, whereas UPAR, tPA and PAI-1 are members of the fibrinolysis pathway [37]. Influenza has been shown to be capable of modulating inflammation and activating coagulation both in vitro and in vivo. Infection of human endothelial cells or monocytes with influenza has been shown to induce procoagulant activity which was associated with an increase in TF expression [11, 12]. In line with this, mice infected with influenza had elevated plasma levels of thrombin-antithrombin complexes, PAI-1 and D-dimer, indicative of a prothrombotic state [13]. Our present findings suggest that influenza-associated coagulation activation at least in part is caused by an imbalance between TF and TFPI expression. Whereas TF mRNA expression was upregulated in lung tissue 8 days after infection, TFPI was downregulated. Remarkably, TF mRNA expression was downregulated in BALF cells and BRUSH during the course of infection, suggesting that interstitial macrophages and/or endothelial cells were the source of TF. In addition, key players in the fibrinolytic system, uPAR, PAI-1 and tPA mRNA were also upregulated in lung tissue. The data on PAI-1 mRNA expression in lungs extend previous reports from our laboratory that docu- mented enhanced pulmonary PAI-1 mRNA during bacterial pneumonia $[38,39]$.

The last group shows genes involved in cell adhesion, tissue repair and cell homeostasis. Of these factors, ICAM-1, HIF- $1 \alpha$ and ITGA- 5 were transiently increased in BALF cells. ITGA-V expression was increased on days 2 and 8 and even further increased on day 14. ITGA-V and subunit $\beta 3$ form a dimer (ITGA-V $\beta 3$ ) which is a receptor for vitronectin, osteopontin and thrombospondin. ITGA-V 33 is expressed on endothelial cells, epithelial cells and leukocytes, and plays a role in cell signaling and migration. However, the role of ITGA-V 33 during influenza infection appears to be limited, considering the expression of $\beta 3$ (i.e. not detectable in BALF cells and reduced in lung homogenates). Our data do not exclude the possibility that ITGA-V interacts with other $\beta$-subunits [40]. ITGA-5 expression was significantly increased in the lungs on day 8 after viral infection. ITGA-5 forms a heterodimer with the $\beta 1$ subunit (ITGA-5 $\beta 1$ ) and binds fibronectin. ITGA-5 $\beta 1$ is exclusively expressed on migrating cells and plays a critical role in wound repair [41]. Whether ITGA-5 $\beta 1$ plays a critical role in the repair of influenza-induced epithelial damage remains to be elucidated.

Pulmonary epithelial cells, macrophages and neutrophils are considered to be sources of MMPs [36]. Infection of epithelial cells with influenza induced MMP-2 mRNA expression [42], while poly(I:C)-stimulated epithelial cells increased secretion of MMP-1, MMPs 8-10 and MMP-13 [36]. MMP-2 and MMP-9 are proteinases which are capable of degrading type IV collagen; thus, they are considered to play an important role in the degeneration of the epithelial cell layer [43]. MMP-2 expression may impair host defense against secondary bacterial infections by disruption of the airway epithelial barrier, thereby enhancing the colonization of invading pathogens. Alternatively, MMP-2 expression may also impair host defense as a consequence of ongoing resolution of inflammatory cells. Both MMP-2 and MMP-9 have recently been implicated in the resolution of inflammatory cells in vivo [44]. Finally, we observed decreased mRNA expression of HP in lung tissue, 14 days after infection. $\mathrm{HP}$ is considered to be an acute-phase protein and has numerous activites during immunological stress, including antioxidant, anti-inflammatory and antibacterial, and it also modulates the immune response [review 45]. Downregulation of HP in the lungs may, therefore, be considered as a potential mechanism by which influenza virus infection alters host defense against secondary infections. 
The roles of several parameters measured in our study have been investigated in detail in other studies by ourselves and by other laboratories using blocking antibodies or knockout mice. In particular, neutralization of TNF- $\alpha$ or IL-1 $\beta$ improved survival rates after influenza virus infection in mice $[46,47]$. Remarkably, mice deficient in IFN- $\gamma$, a prominent antiviral cytokine, showed similar survival rates compared to WT mice when infected with different doses of influenza [48]. Studies done at our laboratory have shown that mice deficient for TLR2 [28] and TLR-4 [33] showed no difference in cytokine production and viral load compared to WT mice. Studies, both in vitro and in vivo, have revealed that cytokine production after influenza infection is, at least in part, dependent on CD14, but its relevance for viral clearance appears to be minimal $[49,50]$. And finally, prothrombotic mice (thrombomodulin TMpro/pro mice) and hyperfibrinolytic PAI-1 knockout mice showed no difference in viral clearance, despite the fact that influenza infection results in a prothrombotic state in vivo [13]. Whether these factors contribute to the response to secondary bacterial infections remains to be established.

We developed a mouse-specific MLPA kit to determine a high-throughput mRNA gene expression to pro- file a broad range of inflammation-related genes. We determined expression of several genes involved in inflammation, TLR signaling and coagulation/fibrinolyis pathway in several pulmonary compartments during infection with influenza in mice. The mouse-specific MLPA could also be used as an adequate tool to determine a wide range of genes in other infection/inflammation models. Our data shows that throughout the course of infection a broad range of genes were differentially expressed, which is in line with results obtained from studies performed earlier. Although expression of most of the genes returned to baseline level, gene expression of uPAR, ITGA-V, ITGB-3, HP and MMP-2 remained altered when the virus was cleared from the lungs and the mice had recovered from the infection.

\section{Acknowledgement}

We would like to thank Joost Daalhuisen and Marieke ten Brink for technical assistance during the animal experiments, and Hella Aberson for technical assistance in MLPA.

\section{References}

1 Murphy BR, Webster RG: Orthomyxoviruses; in Fields BN, Knipe DM, Howley PM (eds): Fields Virology, ed 3. Philadelphia, Lippincott-Raven, 1996, p 1407.

2 Treanor JJ: Orthomyxoviridae: influenza virus; in Mandell GL, Bennett JE, Dolin, R (eds): Principles and Practice of Infectious Diseases, ed 5. New York, Churchill Livingston, 2000, pp 1834-1835.

- 3 Ronni T, Sareneva T, Pirhonen J, Julkunen I: Activation of IFN-alpha, IFN-gamma, MxA, and IFN regulatory factor 1 genes in influenza A virus-infected human peripheral blood mononuclear cells. J Immunol 1995; 154:2764-2774

-4 Tong HH, Long JP, Li D, DeMaria TF: Alteration of gene expression in human middle ear epithelial cells induced by influenza A virus and its implication for the pathogenesis of otitis media. Microb Pathog 2004;37:193204

-5 Julkunen I, Sareneva T, Pirhonen J, Ronni T, Melen K, Matikainen S: Molecular pathogenesis of influenza A virus infection and virus-induced regulation of cytokine gene expression. Cytokine Growth Factor Rev 2001; $12: 171-180$
6 Guillot L, Le Goffic R, Bloch S, et al: Involvement of toll-like receptor 3 in the immune response of lung epithelial cells to doublestranded RNA and influenza A virus. J Biol Chem 2005;280:5571-5580.

-7 Diebold SS, Kaisho T, Hemmi H, Akira S, Reis e Sousa C: Innate antiviral responses by means of TLR7-mediated recognition of single-stranded RNA. Science 2004;303:15291531.

8 Lund JM, Alexopoulou L, Sato A, et al: Recognition of single-stranded RNA viruses by Toll-like receptor 7. Proc Natl Acad Sci USA 2004;101:5598-5603.

-9 Miettinen M, Sareneva T, Julkunen I, Matikainen S: IFNs activate toll-like receptor gene expression in viral infections. Genes Immun 2001;2:349-355.

10 Lee RM, White MR, Hartshorn KL: Influenza a viruses upregulate neutrophil toll-like receptor 2 expression and function. Scand J Immunol 2006;63:81-89.

11 Visseren FL, Bouwman JJ, Bouter KP, Diepersloot RJ, de Groot PH, Erkelens DW: Procoagulant activity of endothelial cells after infection with respiratory viruses. Thromb Haemost 2000;84:319-324.
12 Bouwman JJ, Visseren FL, Bosch MC, Bouter KP, Diepersloot RJ: Procoagulant and inflammatory response of virus-infected monocytes. Eur J Clin Invest 2002;32:759766.

13 Keller TT, van der Sluijs KF, de Kruif MD, et al: Effects on coagulation and fibrinolysis induced by influenza in mice with a reduced capacity to generate activated protein $\mathrm{C}$ and a deficiency in plasminogen activator inhibitor type 1. Circ Res 2006;99:1261-1269.

14 Sakai S, Mantani N, Kogure T, Ochiai H, Shimada Y, Terasawa K: Gene expression of cell surface antigens in the early phase of murine influenza pneumonia determined by a cDNA expression array technique. Mediators Inflamm 2002;11:359-361.

15 Zhang H, Su YA, Hu P, et al: Signature patterns revealed by microarray analyses of mice infected with influenza virus A and Streptococcus pneumoniae. Microbes Infect 2006;8:2172-2185.

16 Engler A, Roy S, Sen CK, Padgett DA, Sheridan JF: Restraint stress alters lung gene expression in an experimental influenza A viral infection. J Neuroimmunol 2005; 162: 103-111. 
-17 Xu W, Zheng S, Goggans TM, et al: Cystic fibrosis and normal human airway epithelial cell response to influenza a viral infection. J Interferon Cytokine Res 2006;26:609-627.

-18 Kawada J, Kimura H, Kamachi Y, et al: Analysis of gene-expression profiles by oligonucleotide microarray in children with influenza. J Gen Virol 2006;87:1677-1683.

19 Diaz-Mitoma F, Alvarez-Maya I, Dabrowski A, et al: Transcriptional analysis of human peripheral blood mononuclear cells after influenza immunization. J Clin Virol 2004;31: $100-112$.

$\checkmark 20$ Cheung CY, Poon LL, Ng IH, et al: Cytokine responses in severe acute respiratory syndrome coronavirus-infected macrophages in vitro: possible relevance to pathogenesis. J Virol 2005;79:7819-7826.

-21 van der Sluijs KF, van elden LJ, Arens R, et al: Enhanced viral clearance in interleukin-18 gene-deficient mice after pulmonary infection with influenza A virus. Immunology 2005;114:112-120.

-22 van der Sluijs KF, van Elden LJ, Xiao Y, et al: IL-12 deficiency transiently improves viral clearance during the late phase of respiratory tract infection with influenza A virus in mice. Antiviral Res 2006;70:75-84.

23 van Elden LJ, Nijhuis M, Schipper P, Schuurman R, van Loon AM: Simultaneous detection of influenza viruses $\mathrm{A}$ and $\mathrm{B}$ using realtime quantitative PCR. J Clin Microbiol 2001;39:196-200.

$\checkmark 24$ Schouten JP, McElgunn CJ, Waaijer R, Zwijnenburg D, Diepvens F, Pals G: Relative quantification of 40 nucleic acid sequences by multiplex ligation-dependent probe amplification. Nucleic Acids Res 2002;30:e57.

-25 Spek CA, Verbon A, Aberson H, et al: Treatment with an anti-CD14 monoclonal antibody delays and inhibits lipopolysaccharideinduced gene expression in humans in vivo. J Clin Immunol 2003;23:132-140.

-26 Maris NA, de Vos AF, Dessing MC, et al: Antiinflammatory effects of salmeterol after inhalation of lipopolysaccharide by healthy volunteers. Am J Respir Crit Care Med 2005; $172: 878-884$

-27 Abruzzo LV, Lee KY, Fuller A, et al: Validation of oligonucleotide microarray data using microfluidic low-density arrays: a new statistical method to normalize real-time RT-PCR data. Biotechniques 2005;38:785792.
28 Dessing MC, van der Sluijs KF, Florquin S, Akira S, van der Poll T: Toll-like receptor2 does not contribute to host response during postinfluenza pneumococcal pneumonia. Am J Respir Cell Mol Biol 2006;36:609-614.

29 van der Sluijs KF, van Elden LJ, Nijhuis M, et al: Involvement of the platelet-activating factor receptor in host defense against Streptococcus pneumoniae during postinfluenza pneumonia. Am J Physiol Lung Cell Mol Physiol 2006;290:L194-L199.

30 Dawson TC, Beck MA, Kuziel WA, Henderson F, Maeda N: Contrasting effects of CCR5 and CCR2 deficiency in the pulmonary inflammatory response to influenza A virus. Am J Pathol 2000;156:1951-1959.

31 Wareing MD, Lyon AB, Lu B, Gerard C, Sarawar SR: Chemokine expression during the development and resolution of a pulmonary leukocyte response to influenza A virus infection in mice. J Leukoc Biol 2004;76:886895.

-32 Hennet T, Ziltener HJ, Frei K, Peterhans E: A kinetic study of immune mediators in the lungs of mice infected with influenza A virus. J Immunol 1992;149:932-939.

33 van der Sluijs KF, van Elden L, Nijhuis M, et al: Toll-like receptor 4 is not involved in host defense against respiratory tract infection with Sendai virus. Immunol Lett 2003;89: 201-206.

34 Bowie AG, Haga IR: The role of Toll-like receptors in the host response to viruses. $\mathrm{Mol}$ Immunol 2005;42:859-867.

35 Seki M, Yanagihara K, Higashiyama Y, et al: Immunokinetics in severe pneumonia due to influenza virus and bacteria coinfection in mice. Eur Respir J 2004;24:143-149.

36 Ritter M, Mennerich D, Weith A, Seither P: Characterization of Toll-like receptors in primary lung epithelial cells: strong impact of the TLR3 ligand poly(I:C) on the regulation of Toll-like receptors, adaptor proteins and inflammatory response. J Inflamm (Lond) 2005;2:16.

$>37$ Levi M, van der Poll T, Buller HR: Bidirectional relation between inflammation and coagulation. Circulation 2004;109:26982704

38 Rijneveld AW, Florquin S, Bresser P, et al: Plasminogen activator inhibitor type-1 deficiency does not influence the outcome of murine pneumococcal pneumonia. Blood 2003;102:934-939.
39 Renckens R, Roelofs JJ, Bonta PI, et al: Plasminogen activator inhibitor type 1 is protective during severe Gram-negative pneumonia. Blood 2006;109:1593-1601.

40 Sheppard D: Functions of pulmonary epithelial integrins: from development to disease. Physiol Rev 2003;83:673-686.

41 Herard AL, Pierrot D, Hinnrasky J, et al: Fibronectin and its alpha 5 beta 1 -integrin receptor are involved in the wound-repair process of airway epithelium. Am J Physiol 1996; 271:L726-L733.

42 Yeo SJ, Kim SJ, Kim JH, Lee HJ, Kook YH: Influenza A virus infection modulates the expression of type IV collagenase in epithelial cells. Arch Virol 1999;144:1361-1370.

43 Collier IE, Wilhelm SM, Eisen AZ, et al: Hras oncogene-transformed human bronchial epithelial cells (TBE-1) secrete a single metalloprotease capable of degrading basement membrane collagen. J Biol Chem 1988;263: 6579-6587.

44 Greenlee KJ, Corry DB, Engler DA, et al: Proteomic identification of in vivo substrates for matrix metalloproteinases 2 and 9 reveals a mechanism for resolution of inflammation. J Immunol 2006;177:7312-7321.

45 Wassell J: Haptoglobin: function and polymorphism. Clin Lab 2000;46:547-552.

$\checkmark 46$ Peper RL, van Campen H: Tumor necrosis factor as a mediator of inflammation in influenza A viral pneumonia. Microb Pathog 1995;19:175-183.

-47 Swiergiel AH, Smagin GN, Johnson LJ, Dunn AJ: The role of cytokines in the behavioral responses to endotoxin and influenza virus infection in mice: effects of acute and chronic administration of the interleukin-1-receptor antagonist (IL-1ra). Brain Res 1997;776: 96-104.

48 Graham MB, Dalton DK, Giltinan D, Braciale VL, Stewart TA, Braciale TJ: Response to influenza infection in mice with a targeted disruption in the interferon gamma gene. J Exp Med 1993;178:1725-1732.

49 Pauligk C, Nain M, Reiling N, Gemsa D, Kaufmann A: CD14 is required for influenza A virus-induced cytokine and chemokine production. Immunobiology 2004;209:310.

50 Dessing MC, Van der Sluijs KF, Florquin S, Van der Poll T: CD14 plays a limited role during influenza virus infection in vivo. Immun Lett 2007;113:47-51. 